\title{
Mortality and Cardiovascular Complications in Older Complex Chronic Patients with Type 2 Diabetes
}

\author{
J. L. Clua-Espuny, ${ }^{1,2}$ M. A. González-Henares, ${ }^{1,3}$ M. L. L. Queralt-Tomas, ${ }^{4}$ \\ W. Campo-Tamayo, ${ }^{5}$ E. Muria-Subirats, ${ }^{5}$ A. Panisello-Tafalla, ${ }^{6}$ and J. Lucas-Noll ${ }^{7}$ \\ ${ }^{1}$ Department of Research, ICS Terres de l'Ebre, University Institute in Primary Care Research Jordi Gol (IDIAP Jordi Gol), \\ Barcelona, Spain \\ ${ }^{2}$ EAP-Camarles-Aldea-Ampolla, Catalonian Health Institute, SAP Terres de l'Ebre, Health Department, Generalitat de Catalunya, \\ CAP Ampolla, 43895 Tortosa, Spain \\ ${ }^{3}$ EAP Tortosa 1-Est, Catalonian Health Institute, SAP Terres de l'Ebre, Health Department, Generalitat de Catalunya, CAP Temple, \\ 43500 Tortosa, Spain \\ ${ }^{4}$ EAP Tortosa-2-Oest, Catalonian Health Institute, SAP Terres de l'Ebre, Health Department, Generalitat de Catalunya, CAP Xerta, \\ Barcelona, 43592 Catalonia, Spain \\ ${ }^{5}$ UUDD Tortosa-Terres de l'Ebre, CAP Temple, EAP Tortosa Est, Institut Català de la Salut, 43500 Tortosa, Spain \\ ${ }^{6}$ EAP-Camarles-Aldea-Ampolla, Catalonian Health Institute, SAP Terres de l'Ebre, Health Department, Generalitat de Catalunya, \\ CAP Camarles, 43894 Tortosa, Spain \\ ${ }^{7}$ EAP-Alcanar-St Carles de la Rápita, Catalonian Health Institute, SAP Terres de l'Ebre, Health Department, Generalitat de Catalunya, \\ CAP St Carles de la Rápita, 43894 Tortosa, Spain
}

Correspondence should be addressed to J. L. Clua-Espuny; jlclua.ebre.ics@gencat.cat

Received 3 April 2017; Accepted 10 July 2017; Published 10 August 2017

Academic Editor: Charbel Abi Khalil

Copyright (C) 2017 J. L. Clua-Espuny et al. This is an open access article distributed under the Creative Commons Attribution License, which permits unrestricted use, distribution, and reproduction in any medium, provided the original work is properly cited.

\begin{abstract}
Aims/Introduction. Determining the prevalence of diabetes and its cardiovascular complications and all-cause mortality in older chronic complex patients. Materials and Methods. We carried out a multicenter retrospective study and included a randomized sample of 932 CCP people. We assessed the prevalence of diabetes according to World Health Organization criteria. Data included demographics and functional, comorbidity, cognitive, and social assessment. Results. The prevalence of diabetes was 53\% and average age $81.16 \pm 8.93$ years. There were no significant differences in the survival of CCP patients with or without DM, with or without ischaemic cardiopathy, and with or without peripheral vascular disease. The prognostic factors of all-cause mortality in patients with DM were age $\geq 80$ years [HR 1.47, 95\% CI 1.02-2.13, p 0.038], presence of heart failure [HR 1.73, 95\% CI 1.25-2.38, $p$ 0.001], Charlson score [HR 1.20, 95\% CI 1.06-1.36, p 0.003], presence of cognitive impairment [HR 1.73, 95\% CI 1.24-2.40, p 0.001], and no treatment with statins [HR 1.49, 95\% CI 1.08-2.04, p 0.038]. Conclusions. We found high prevalence of DM among CCP patients and the relative importance of traditional risk factors seemed to wane with advancing age. Recommendations may include relaxing treatment goals, providing family/patient education, and enhanced communication strategies.
\end{abstract}

\section{Introduction}

The World Health Organization [1] has reported an increase in the ageing population living with major chronic diseases such as diabetes, dementia, cardiovascular disease, and certain cancers, with most of the increase in developing countries. Health experts have called this phenomenon the "grey tsunami" [2] due to its impact on the health system.
Type- 2 diabetes is one of the most common chronic diseases affecting older people and its prevalence increases with age. It has been estimated that the number of people over 65 with diabetes will increase by 4.5 -fold by 2050 [3]; and diabetes is linked to higher mortality, reduced functional status, impaired quality of life, increased risk of institutionalization [4], and mortality. 
Several publications have described the spectrum of comorbidities and functional impairment in ageing populations [5-7]. They emphasize a number of key features such as the emergence of cognitive dysfunction and frailty that can worsen adverse outcomes of diabetes such as emergency visits, increased fall risk, and mortality. The main goal of this study was to determine the prevalence of diabetes and its cardiovascular complications and all-cause mortality in complex chronic patients.

\section{Materials and Methods}

2.1. Study Population and Data Collection. This cohort study (2013-2016) included 3,490 cases registered as complex chronic patient enrolled in a large, integrated health primary care teams in the Terres de l'Ebre health area in Catalonia (Spain) with a sampling frame that included a randomized sample of 932 members. The source population was identified from the Catalonian Health Institute Registry as of 1 January 2013 to 31 December 2014. We included subjects if they met at least four of the following criteria: (1) age ( $\geq 65$ years old), (2) chronic comorbidities ( $\geq 4$ ), (3) psychosocial disorders (cognitive impairment or psychological disorder with functional disability), (4) geriatric conditions such as functional disability (Barthel score $<55$, living in assisted living, in nursing home, or with in-home caregivers) or recurrent falls or fall risk, (5) previous high healthcare use (two hospitalizations not programmed for exacerbation of chronic pathologies or three emergency department visits in the last year), (6) $\geq 4$ active medications in the last 6 months, and (7) living alone or with a caregiver $\geq 75$ years old. Established in January 2013, the registry is written, managed, and updated by the nursing service in primary care using the Shared Individual Intervention Plan [pla d'intervenció individualitzat compartit (PIIC)]. Follow-up of this cohort members was initiated on 1 January 2013, and individuals were censored at the first occurrence of death that had occurred from any cause or at the end of the study (30 September 2016).

2.2. Variables. We collected data on demographic characteristics and data related to clinical, functional, cognitive, and social assessment. Comorbid conditions are defined using standard outpatient and inpatient ICD-9 codes by electronic data capture including pharmacy records, laboratory data, and outpatient, emergency room, and hospitalization diagnoses across all primary care centers and hospital. Charlson comorbidity index, short version, was scored. Polypharmacy was defined as five or more daily medications. If there was a diagnosis of atrial fibrillation (AF), $\mathrm{CHA}_{2} \mathrm{DS}_{2} \mathrm{VAS}_{\mathrm{C}} \mathrm{HAS}$-BLED scores were included. Presence of cognitive impairment, a disease-specific diagnosis of cognitive impairment, without specification of subtype or severity, was measured using the Pfeiffer test. The variable definition includes recurrent falls or fall risk and presence of disability by Barthel score to assess dependence in ADL.

Currently, $82 \%$ of people registered as CCP have available clinical data in their PIIC report.
2.3. Criteria for the Definition of Diabetes. Diabetes (DM) was diagnosed according to any of the following WHO criteria: fasting plasma glucose (FPG) $\geq 7.0 \mathrm{mmol} / \mathrm{l}(126 \mathrm{mg} / \mathrm{dl})$ or $75 \mathrm{~g}$ oral glucose tolerance test (OGTT) with FPG $\geq 7.0 \mathrm{mmol} / \mathrm{l}$ $(126 \mathrm{mg} / \mathrm{dl})$ and/or 2-hour plasma glucose $\geq 11.1 \mathrm{mmol} / \mathrm{l}$ $(200 \mathrm{mg} / \mathrm{dl})$ or $\mathrm{HbAlc} \geq 6.5 \% / 48 \mathrm{mmol} / \mathrm{mol}$ or random plasma glucose $\geq 11.1 \mathrm{mmol} / \mathrm{l}(200 \mathrm{mg} / \mathrm{dl})$ in the presence of classical diabetes symptoms.

2.4. Statistical Analysis. Time to event analysis was performed using the Kaplan-Meier and Log Rank test. To estimate hazard ratios, mean survival time, and survival probabilities, we used a multivariate Cox regression. Multivariate Cox proportional hazards regression models were fitted to identify significant variables associated with the time to death since diagnosis as CCP. The adjusted model included the following baseline characteristics and the differences observed between DM and no DM and predictive factors for each event: age, sex, Charlson index, and factors in $\mathrm{CHA}_{2} \mathrm{DS}_{2} \mathrm{VAS}_{\mathrm{C}}$ scales and active pharmacy. The analyses were performed using IBM SPSS version 19.0.

\section{Results}

The baseline characteristics of the CCP group are shown in Table 1 . The prevalence of CCP was $1.94 \%$ in the total population and $7.01 \%$ in those $\geq 60$ years old. Diabetes had been diagnosed in $53 \%$ of the CCP population, with an average age of $81.16 \pm 8.93$ years, significantly younger $(p<$ $0.001)$ than those CCP without DM, but with a higher cardiovascular risk ( $p$ 0.015), a higher risk of stroke $(p<$ $0.001)$, more chronic conditions $(p<0.001)$, and a higher number of prescribed drugs $(p<0.001)$, but a higher Barthel score $(p$ 0.003) and lower prevalence of cognitive impairment ( $p$ 0.001).

The patients were divided into three major subgroups defined jointly by age $(<70,70-79$, and $\geq 80$ years $)$ and prevalence of cardiovascular complications (Table 2 ). There was a steady increase in the prevalence of cardiovascular comorbidities such as atrial fibrillation and heart failure, cognitive impairment, loss of autonomy in basic daily activities, increased fall risk, and the all-cause mortality rates associated with ageing. Other traditional risk factors associated with diabetes such as hypertension, dyslipidemia, and macrovascular complications such as ischaemic cardiopathy and peripheral artery disease stayed the same or even decreased with ageing.

The average follow-up time was 2.75 years (95\% CI $2.42-3.07)$. The all-cause mortality rate was $32.8 \%$ in DM and $35.8 \%$ in non-DM patients. The incidence rate of death was $13.1 / 100$ person-years in DM and 11.7/100 person-years in non-DM patients. There were no significant survival differences (Figure 1) between those with or without DM, with or without ischaemic cardiopathy (Figure 2), or with or without peripheral artery disease. There was a significant survival difference in the case of atrial fibrillation ( $p$ 0.003) (Figure 3 ) and heart failure $(p<0.001)$ (Figure 4$)$. Table 3 shows number of deaths by decade of age.

In the CCP population with DM the prognostic mortality factors identified by the multivariate method were 
TABLE 1: Baseline characteristics of CCP with and without diabetes.

\begin{tabular}{|c|c|c|c|}
\hline CCP patients & No diabetes & Diabetes & $p$ \\
\hline$N(\%)$ & $438(47.00 \%)$ & $494(53.00 \%)$ & \\
\hline Age (average $\pm \mathrm{SD}$ ) & $84.22 \pm 10.6$ & $81.16 \pm 8.0$ & $<0.00$ \\
\hline $\begin{array}{l}\text { Percentage }>80 \text { years old } \\
n(\%)\end{array}$ & $340(77.6 \%)$ & $315(63.8 \%)$ & $<0.00$ \\
\hline Women $n(\%)$ & $236(53.9 \%)$ & $252(51.0 \%)$ & 0.394 \\
\hline $\begin{array}{l}\text { CCP criteria number } \\
\text { (average } \pm \mathrm{SD} \text { ) }\end{array}$ & $3.85 \pm 1.26$ & $3.86 \pm 1.12$ & 0.955 \\
\hline Hypertension $n(\%)$ & $362(80.4 \%)$ & $422(85.4 \%)$ & 0.044 \\
\hline Dyslipidemia $n(\%)$ & $195(44.5 \%)$ & $326(66.0 \%)$ & $<0.001$ \\
\hline Atrial fibrillation $n(\%)$ & $176(40.2 \%)$ & $149(30.2 \%)$ & 0.002 \\
\hline Ischaemic cardiopathy $n(\%)$ & $87(19.9 \%)$ & $109(22.1 \%)$ & 0.422 \\
\hline $\begin{array}{l}\text { Peripheral artery disease } \\
n(\%)\end{array}$ & $58(13.2 \%)$ & $91(18.4 \%)$ & 0.032 \\
\hline $\begin{array}{l}\text { Chronic kidney insufficiency } \\
<30 \mathrm{mlClCr}\end{array}$ & $43(9.8 \%)$ & $73(14.7 \%)$ & 0.042 \\
\hline Heart failure $n(\%)$ & $153(34.9 \%)$ & $150(30.4 \%)$ & 0.142 \\
\hline $\begin{array}{l}\text { Charlson sc } \\
\text { (average } \pm S\end{array}$ & $2.05 \pm 1.30$ & $2.95 \pm 1.30$ & 0.015 \\
\hline Stroke before CCP $n$ & $104(23.7 \%)$ & $96(19.4 \%)$ & 0.111 \\
\hline Stroke after CCP $n(\%)$ & $36(8.2 \%)$ & $30(6.1 \%)$ & 0.249 \\
\hline $\begin{array}{l}\mathrm{CHA}_{2} \mathrm{DS}_{2} \mathrm{VAS}_{\mathrm{C}} \text { score } \\
\text { (average } \pm \mathrm{SD} \text { ) }\end{array}$ & $5.97 \pm 2.38$ & $7.14 \pm 5.97$ & $<0.00$ \\
\hline $\begin{array}{l}\text { HAS_BLED score } \\
\text { (average } \pm \text { SD) }\end{array}$ & $2.88 \pm 1.14$ & $3.10 \pm 1.05$ & 0.077 \\
\hline $\begin{array}{l}\text { ations number } \\
\text { D) }\end{array}$ & $7.8 \pm 3.29$ & $9.80 \pm 3.60$ & $<0.001$ \\
\hline Polypharmacy $\geq 4 n(\%)$ & $392(89.5 \%)$ & $484(98 \%)$ & $<0.001$ \\
\hline Polypharmacy $\geq 10 n(\%)$ & $142(32.4 \%)$ & $258(52.2 \%)$ & $<0.001$ \\
\hline Cognitive impairment $n(\%)$ & $179(40.9 \%)$ & $159(32.2 \%)$ & 0.006 \\
\hline $\begin{array}{l}\text { Pfeiffer test score } \\
\text { (average } \pm \text { SD) }\end{array}$ & $3.43 \pm 3.39$ & $2.72 \pm 3.13$ & 0.001 \\
\hline Barthel score (average \pm SD) & $62.8 \pm 32.41$ & $69.02 \pm 31.28$ & 0.003 \\
\hline Barthel score < $60 n(\%)$ & $182(41.6 \%)$ & $161(32.6 \%)$ & 0.005 \\
\hline Fall risk $n(\%)$ & $103(23.9 \%)$ & $85(17.2 \%)$ & 0.018 \\
\hline Gijón score (average \pm SD) & $9.53 \pm 5.12$ & $10.46 \pm 3.87$ & 0.363 \\
\hline $\begin{array}{l}\text { Antiaggregant treatment } \\
n(\%)\end{array}$ & $147(33.6 \%)$ & $238(48.2 \%)$ & $<0.001$ \\
\hline $\begin{array}{l}\text { Anticoagulant treatment } \\
n(\%)\end{array}$ & $147(33.6 \%)$ & $123(24.9 \%)$ & 0.003 \\
\hline Statin treatment $n(\%)$ & $149(34.0 \%)$ & $274(55.5 \%)$ & $<0.00$ \\
\hline $\begin{array}{l}\text { Proton pump inhibitor } \\
\text { treatment } n(\%)\end{array}$ & $285(65.1 \%)$ & $358(72.5 \%)$ & 0.016 \\
\hline $\begin{array}{l}\text { Selective serotonin reuptake } \\
\text { inhibitors (SSRIs) } n(\%)\end{array}$ & $131(29.9 \%)$ & $149(30.2 \%)$ & \\
\hline CNS depressant drugs $n(\%)$ & $249(56.8 \%)$ & $265(53.6 \%)$ & 0.356 \\
\hline Death $n(\%)$ & $157(35.8 \%)$ & $162(32.8 \%)$ & 0.334 \\
\hline
\end{tabular}

age $\geq 80$ years [HR 1.47, 95\% CI 1.02-2.13, “ $p$ 0.038”], heart failure [HR 1.73, 95\% CI 1.25-2.38, “ $p 0.001$ ”], the Charlson score [HR 1.20, 95\% CI 1.06-1.36, “ $p$ 0.003”], cognitive impairment [HR 1.73, 95\% CI 1.24-2.40, “p 0.001”],

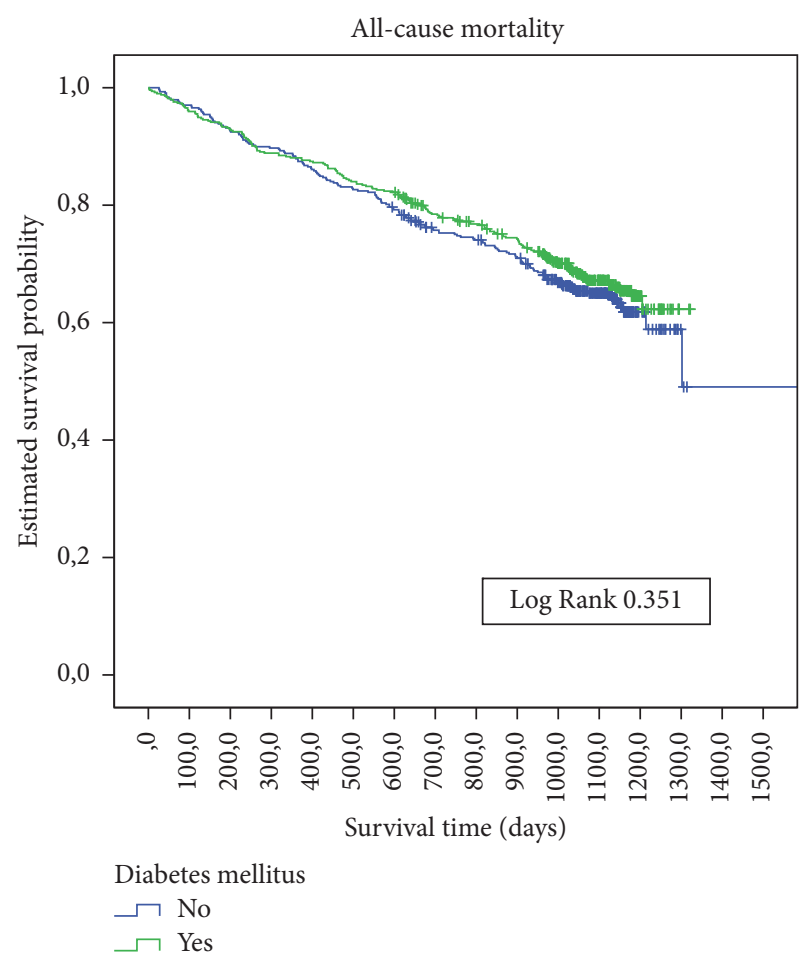

FIgURE 1: Kaplan-Meier estimates of survival during follow-up in CCP with or without diabetes mellitus at baseline.

and no treatment with statins [HR 1.49, 95\% CI 1.08-2.04, "p 0.038"].

We can define an epidemiological model with a high prevalence of DM (53\%) associated with classical risk factors such as hypertension (84.1\%), dyslipidemia (52.1\%), atrial fibrillation (37.9\%), and stroke $(28.3 \%)$ to which other risk factors can be added such as age $\geq 80$ years (70.2\%), cognitive impairment (44.1\%), heart failure (35.6\%), CNS depressant drugs (56.9\%), fall risk (23.2\%), and the lowest Barthel score (59, 95\% CI 57.1-62.08), all of which increase the risk of mortality.

\section{Discussion}

The registered prevalence of CCP in our study was higher than in other developed countries [8] as was the prevalence of diabetes mellitus in our CCP population $[2,9,10]$. The frequency of comorbidity burden such as cognitive impairment, polypharmacy, functional disability of basic activities of daily living, and limited availability of caregiver support may be a substantial problem in implementing a management plan. A consensus has developed on how to treat older people with diabetes [11,12], but given that complications may not be present or may take many years to develop, efforts should be adapted depending on the average remaining life expectancy and degree of impairment of quality of life.

The authors believe a strategic change will involve moving away from "the diabetic patient with complications" to "CCP with chronic comorbidities." Therefore, while classically diabetes mellitus has been associated with the development 
TABLE 2: Baseline characteristics of CCP patients according to age.

\begin{tabular}{|c|c|c|c|}
\hline CCP patients & $<70$ years old & $70-79$ years old & $\geq 80$ years old \\
\hline$N(\%$ all $)$ & $93(9.97 \%)$ & 184 & 655 \\
\hline Age (average CI 95\%) & $61.39(59.6-63.1)$ & $75.6(75.2-76.02)$ & $87.5(87.2-87.9)$ \\
\hline Women $n$ (\% group) & $41 / 93=44.08 \%$ & $82(44.6 \%)$ & $365(55.7 \%)$ \\
\hline CCP criteria number (average CI 95\%) & $2.9(2.7-3.22)$ & $3.69(3.5-3.8)$ & $4.02(3.94-4.12)$ \\
\hline Diabetes mellitus $n$ (\% group) & $53(57 . \%)$ & $125(67.9 \%)$ & $16(48.2 \%)$ \\
\hline Hypertension $n$ (\% group) & $63(67.7 \%)$ & $160(87.0 \%)$ & $551(84.1 \%)$ \\
\hline Dyslipidemia $n$ (\% group) & $55(59.1 \%)$ & $125(67.9 \%)$ & $341(52.1 \%)$ \\
\hline Atrial fibrillation $n$ (\% group) & $17(18.3 \%)$ & $60(32.6 \%)$ & $248(37.9 \%)$ \\
\hline Ischaemic cardiopathy $n$ ( $\%$ group) & $20(21.5 \%)$ & $43(23.4 \%)$ & $133(20.3 \%)$ \\
\hline Peripheral artery disease $n$ (\% group) & $17(18.3 \%)$ & $41(22.3 \%)$ & $91(13.9 \%)$ \\
\hline Chronic kidney insufficiency $<30 \mathrm{mlClCr} n$ (\% group) & $12(12.9 \%)$ & $24(13.1 \%)$ & $80(12.2 \%)$ \\
\hline Heart failure $n$ (\% group) & $17 / 93=18.27 \%$ & $53(28.8 \%)$ & $233(35.6 \%)$ \\
\hline Charlson score (average CI 95\%) & $2.17(1.87-2.47)$ & $2.7(2.5-2.9)$ & $2.52(2.42-2.63)$ \\
\hline Stroke $n$ (\% group) & $21(22.6 \%)$ & $51(27.8 \%)$ & $185(28.3 \%)$ \\
\hline $\mathrm{CHA}_{2} \mathrm{DS}_{2} \mathrm{VAS}_{\mathrm{C}}$ score (average CI 95\%) & $4(3.11-4.9)$ & $5.17(4.84-5.51)$ & $5.03(4.88-5.20)$ \\
\hline Stroke risk/year (average CI 95\%) & $4.78(3.55-6.02)$ & $6.81(6.2-7.4)$ & $6.57(6.27-6.87)$ \\
\hline Daily medications number (average CI 95\%) & $9.21(8.37-10.6)$ & $10.1(9.5-10.53)$ & $8.5(8.24-8.77)$ \\
\hline Cognitive impairment $n$ (\% group) & $14(15.1 \%)$ & $35(19.0 \%)$ & $289(44.1 \%)$ \\
\hline Pfeiffer test score (average CI 95\%) & $1.40(0.86-1.95)$ & $1.53(1.19-1.89)$ & $3.71(3.46-3.97)$ \\
\hline Barthel score (average CI 95\%) & $82.8(77.3-88.4)$ & $80.67(76.9-84.4)$ & 59. $(57.1-62.08)$ \\
\hline Fall risk $n$ (\% group) & $5(5.4 \%)$ & $31(16.8 \%)$ & $152(23.2 \%)$ \\
\hline Antiaggregant treatment $n$ (\% group) & $30(32.3 \%)$ & $82(44.6 \%)$ & $273(41.7 \%)$ \\
\hline Anticoagulant treatment $n$ (\% group) & $25(26.9 \%)$ & $55(29.9 \%)$ & $175(26.7 \%)$ \\
\hline HAS_BLED (average CI 95\%) & $2.93(2.22-3.65)$ & $3.06(2.81-3.31)$ & $2.96(2.82-3.11)$ \\
\hline Bleeding risk/year (average CI 95\%) & $5.18(3.0-7.37)$ & $4.89(4.0-5.8)$ & $4.95(4.5-5.41)$ \\
\hline Statin treatment $n$ (\% group) & $54(58.1 \%)$ & $118(64.1 \%)$ & $251(38.3 \%)$ \\
\hline CNS depressant drugs $n$ (\% group) & $44(47.3 \%)$ & $97(52.7 \%)$ & $373(56.9 \%)$ \\
\hline Death $n$ (\% group) & $12(12.9 \%)$ & $48(26.1 \%)$ & $259(39.5 \%)$ \\
\hline Average follow-up time $n$ (days CI 95\%) & $1348(719-1977)$ & 947 (901-993) & $971(825-1117)$ \\
\hline
\end{tabular}

of micro and macrovascular complications, with an ageing population, it is not yet clear whether the presence of chronic cardiovascular comorbidities or a higher risk of undergoing acute cardiovascular events (higher $\mathrm{CHA}_{2} \mathrm{DS}_{2} \mathrm{VAS}_{\mathrm{C}}$ score) should be approached as preventable and modifiable risk factors (antiaggregant, statins) or as one more condition of the "chronic complex patient" that needs to be controlled but without benefits for cardiovascular risk.

Given that it is unknown how long the DM is running and that most risk score tables exclude $75 \%$ of our CCP due to their age, the use of such tables is pointless because we cannot relate the cardiovascular complication rates to a risk score. On the other hand, strategies to modify the incremental tendency for DM involving the promotion of healthy lifestyles (mainly associated with diet and physical activities) and the detection of high risk patients are difficult to apply at this vital stage. The priorities should be avoiding or lowering the risk of complications (hypoglycemia, hyperglycemia, fall, and polypharmacy) via an appropriate stratification using the functional autonomy based on adaptations to individual environments. The literature related to interventions for lifestyle diseases in developing countries is very limited, probably due to the multitude of possible health endpoints and interventions, the multiple sources of the problem, and the limited knowledge of means of changing individual and population behavior [13-15].

In contrast with other studies [16], our results show that the incidence of all-cause mortality and the prevalence of cardiovascular diseases do not differ significantly among CCP with and without DM. The data about deaths related to diabetes are confusing and come from different age cohorts: according to the World Health Organization, 43\% of all deaths due to high blood glucose occur before the age of 70 [17]; and the proportion of deaths attributable to diabetes was estimated to be $11.5 \%$ in the United States $[18,19]$. In our study the mortality rate due to diabetes was $17 \%$, and $<70$ years old is when the difference in mortality is higher between DM and no DM. This fact supports our thought of a different epidemiologic profile in this group of population. However, we found risk factors associated with ageing such as cognitive impairment and heart failure that have been described previously as prognostic factors for mortality [5-7] in the CCP population. This supports the idea that all-cause mortality is more affected by ageing factors than by specific 


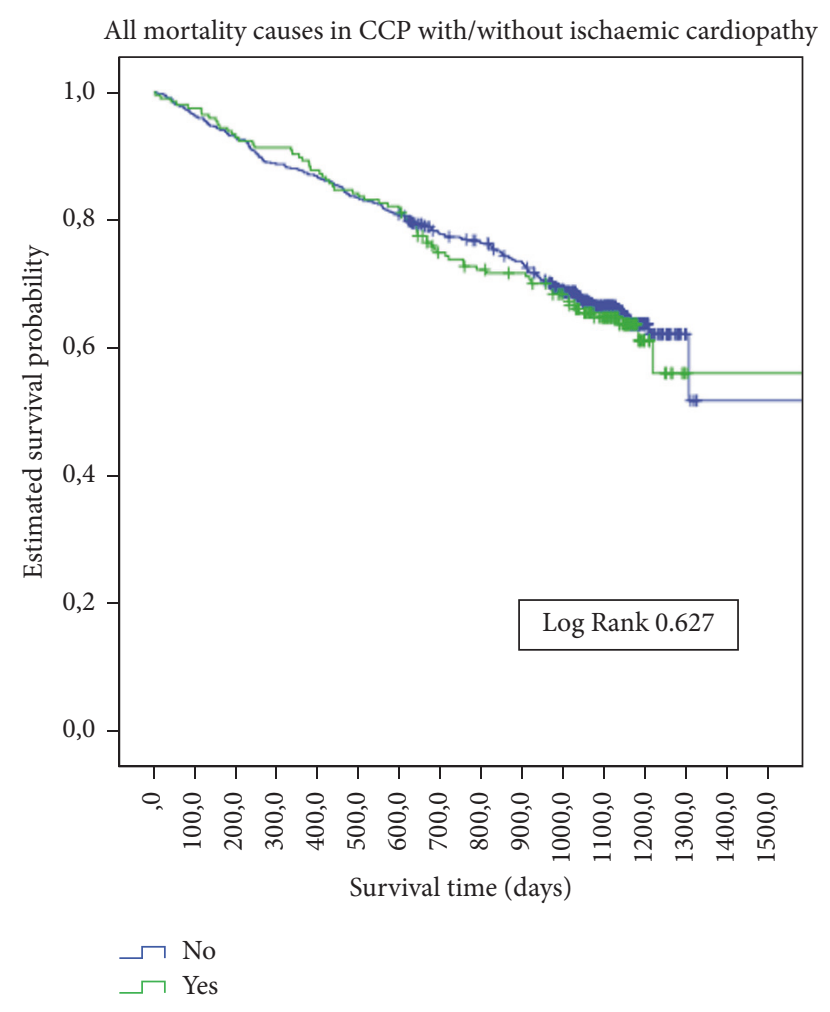

Figure 2: Kaplan-Meier estimates of survival during follow-up in CCP with or without ischaemic cardiopathy at baseline.

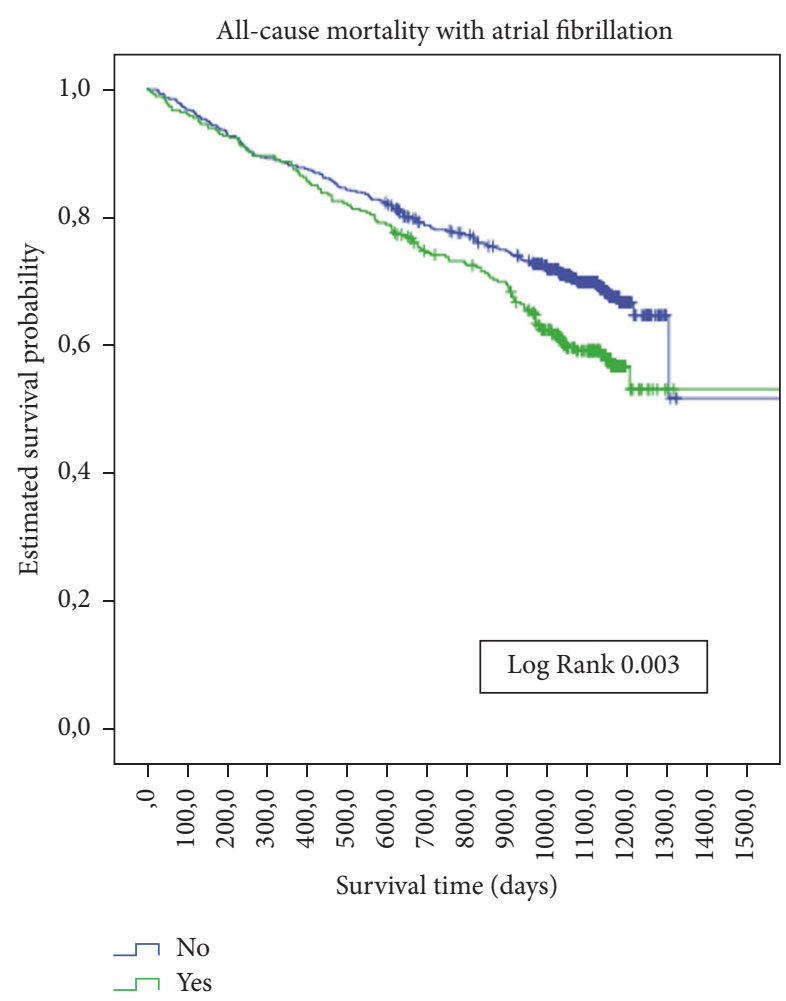

FIGURE 3: Kaplan-Meier estimates of survival during follow-up in CCP with or without atrial fibrillation at baseline.

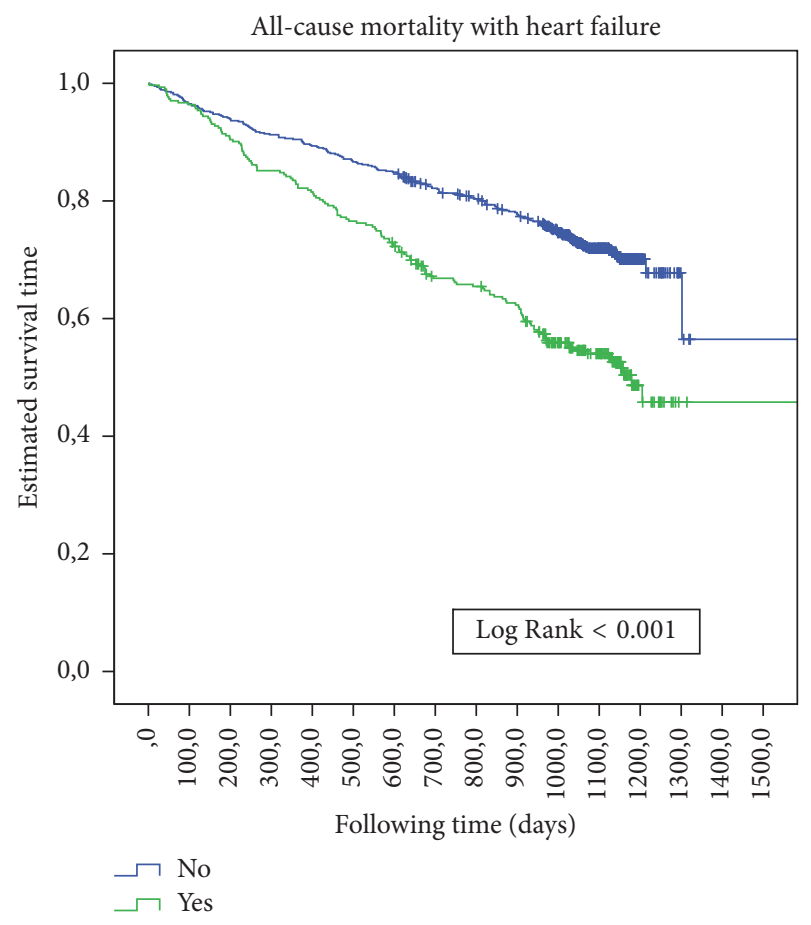

FIGURE 4: Kaplan-Meier estimates of survival during follow-up in CCP with and without heart failure at baseline.

TABLE 3: Number of deaths according to age.

\begin{tabular}{lcccc}
\hline Age & $\begin{array}{c}\text { Diabetes } \\
N(\%)\end{array}$ & $\begin{array}{c}\text { No diabetes } \\
N(\%)\end{array}$ & $p$ & All \\
\hline $\begin{array}{l}<0 \\
(n 93)\end{array}$ & $9(17.0 \%)$ & $3(7.5 \%)$ & 0.150 & $12(12.9 \%)$ \\
$70-79$ & $32(25.6 \%)$ & $16(27.1 \%)$ & 0.480 & $48(26.1 \%)$ \\
$n(184)$ & & $72(35.8 \%)$ & 0.361 & $146(33.6 \%)$ \\
$\begin{array}{l}80-89 \\
n(435)\end{array}$ & $74(31.6 \%)$ & $66(47.8 \%)$ & 0.209 & $113(51.4 \%)$ \\
$\geq 90$ & $47(57.3 \%)$ & $157(35.8 \%)$ & 0.181 & $319(34.2 \%)$ \\
$\begin{array}{l}n(220) \\
\text { Total } \\
(n 932)\end{array}$ & $162(32.8 \%)$ & & & \\
\hline
\end{tabular}

complications of DM. Likewise the incidence of DM in this CCP population may be more of a consequence of the ageing process than an independent disease. The comorbidities may drive all-cause mortality and the contribution of diabetes in the presence of complex chronic diseases to overall mortality seems to be only minimal.

Despite the above, we should not underestimate the importance of evaluating and treating cardiovascular risk given that it plays a key role in cardiovascular prevention in all national and international guidelines [20], mainly among patients with a high level of functional dependence. The relative importance of traditional risk factors seems to wane with advancing age [21] and for this reason; we emphasize the importance of redefining the care strategy and adapting it to comorbidities and functional autonomy rather than 
achieving excellent levels of glycated haemoglobin or total cholesterol.

The limitations of the present approach are related to the possibility of overestimating the prevalence of DM among the CCP population as a consequence of the definition criteria despite being a randomized sample; not knowing the duration of DM in order to prevent complications; and perhaps the frequency with which diabetes is listed as the underlying cause of death is not a reliable indicator of its contribution to the mortality profile. Also, we need to determine accurately whether diabetes was the underlying cause of death or was only an associated cause of death.

\section{Conflicts of Interest}

The authors declare that there are no conflicts of interest regarding the publication of this paper.

\section{Acknowledgments}

The authors thank the Research Group Ebrictus participants. M. A. González-Henares has received project and fellowship grants from the University Institute in Primary Care Research Jordi Gol (IDIAP Jordi Gol) of Catalonia (Spain).

\section{References}

[1] R. Suzman and J. Beard, "Global health and aging: preface. National Institute on Aging website," 2011, https://www.nia.nih .gov/health/topics?field_a_to_z_topics_index_target_id=Advance \%20care\%20planning\%20\%283586\%29.

[2] PolicyMatters.ca, "Expert perspectives on select areas of Canadian health policy," 2017, http://www.policymatters.ca/.

[3] K. M. V. Narayan, J. P. Boyle, L. S. Geiss, J. B. Saaddine, and T. J. Thompson, "Impact of recent increase in incidence on future diabetes burden: U.S., 2005-2050," Diabetes Care, vol. 29, no. 9, pp. 2114-2116, 2006.

[4] M. S. Kirkman, V. J. Briscoe, N. Clark et al., "Diabetes in older adults," Diabetes Care, vol. 35, no. 12, pp. 2650-2664, 2012.

[5] J. L. Clua-Espuny, M. A. González-Henares, M. L. L. QueraltTomas, and V. F. Gil-Guillen, "Polypharmacy and mortality among chronic complex outpatients: Results of communitybased prospective study," International Journal of Medical Research and Pharmaceutical Sciences, vol. 3, no. 11, 2016.

[6] M. A. González-Henares, J. L. Clua-Espuny, M. L. L. QueraltTomas, A. Panisello-Tafalla, R. Ripolles-Vicente, W. CampoTamayo et al., "Falls risk and mortality among chronic complex outpatients: results of community-based prospective study," Gerontology and Geriatrics Research, vol. 2, no. 5, article 1024, 2016.

[7] JL. Clua-Espuny, M. A. González-Henares, M. L. L. QueraltTomas et al., "Atrial fibrillation and cognitive impairment: a growing association. Occurrence of death among chronic complex outpatients," EC Cardiology, pp. 226-239, 2016.

[8] European Union Health Policy Forum Answer to DG SANCO consultation on chronic diseases, 2012, https://ec.europa.eu/ health//sites/health/files/interest_groups/docs/euhpf_answer_ consultation_jan2012_en.pdf.
[9] J. B. Halter, "Diabetes mellitus in an aging population: The challenge ahead," Journals of Gerontology - Series A Biological Sciences and Medical Sciences, vol. 67, no. 12, pp. 1297-1299, 2012.

[10] H. Charvat, A. Goto, M. Goto et al., "Impact of population aging on trends in diabetes prevalence: a meta-regression analysis of 160,000 Japanese adults," Journal of Diabetes Investigation, vol. 6, no. 5, pp. 533-542, 2015.

[11] M. Sue Kirkman, V. J. Briscoe, N. Clark et al., "Diabetes in older adults: a consensus report," Journal of the American Geriatrics Society, vol. 60, no. 12, pp. 2342-2356, 2012.

[12] "European Diabetes working party for older people 2011. Clinical guidelines for type 2 diabetes mellitus. Executive summary," Diabetes and Metabolism, vol. 37, pp. S27-S38, 2011.

[13] J. M. Fair, "Cardiovascular risk factor modification: is it effective in older adults?" The Journal of Cardiovascular Nursing, vol. 18, no. 3, pp. 161-168, 2003.

[14] J. W. Davis, R. Chung, and D. T. Juarez, "Prevalence of comorbid conditions with aging among patients with diabetes and cardiovascular disease.", Hawaii medical journal, vol. 70, no. 10, pp. 209-213, 2011.

[15] N. Versnel, L. M. Welschen, C. A. Baan, G. Nijpels, and F. G. Schellevis, "The effectiveness of case management for comorbid diabetes type 2 patients; The CasCo study. Design of a randomized controlled trial," BMC Family Practice, vol. 12, article 68, 2011.

[16] E. S. Huang, N. Laiteerapong, J. Y. Liu, P. M. John, H. H. Moffet, and A. J. Karter, "Rates of complications and mortality in older patients with diabetes mellitus: the diabetes and aging study," JAMA Internal Medicine, vol. 174, no. 2, pp. 251-258, 2014.

[17] World Health Organization, "Global report on diabetes," 2016, http://www.who.int/en/.

[18] A. Stokes and S. H. Preston, "Deaths attributable to diabetes in the United States: Comparison of data sources and estimation approaches," PLoS ONE, vol. 12, no. 1, article e0170219, 2017.

[19] H. E. Mulnier, H. E. Seaman, V. S. Raleigh, S. S. SoedamahMuthu, H. M. Colhoun, and R. A. Lawrenson, "Mortality in people with type 2 diabetes in the UK," Diabetic Medicine, vol. 23, no. 5, pp. 516-521, 2006.

[20] IDF Global Guideline for Managing Older People with Type 2 Diabetes. International Diabetes Federation, 2013, https://www .idf.org/.

[21] M. T. Koller, M. J. G. Leening, M. Wolbers et al., "Development and validation of a coronary risk prediction model for older U.S. and european persons in the cardiovascular health study and the rotterdam study," Annals of Internal Medicine, vol. 157, no. 6, pp. 389-397, 2012. 


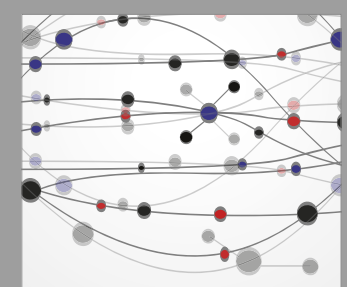

The Scientific World Journal
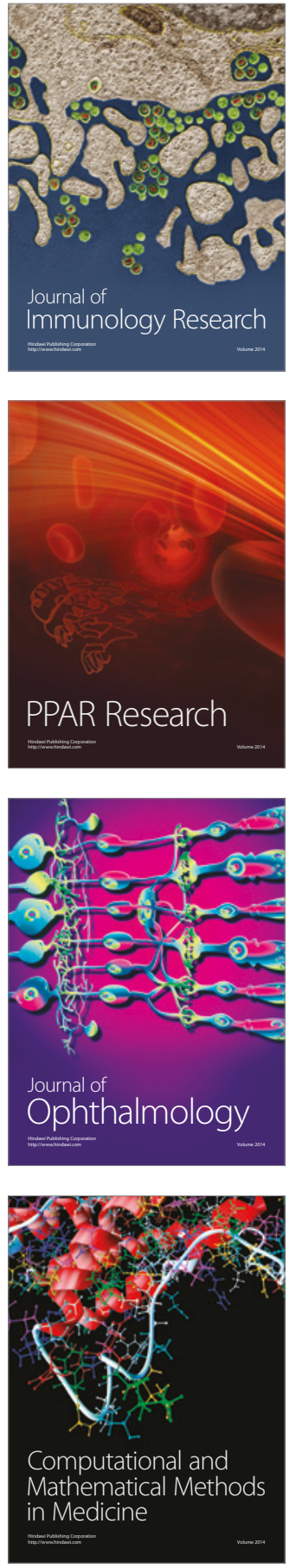

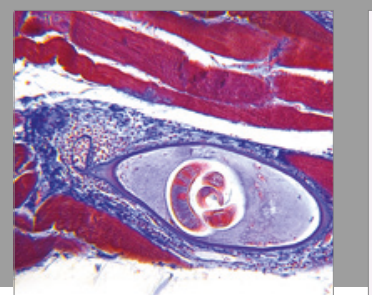

Gastroenterology Research and Practice
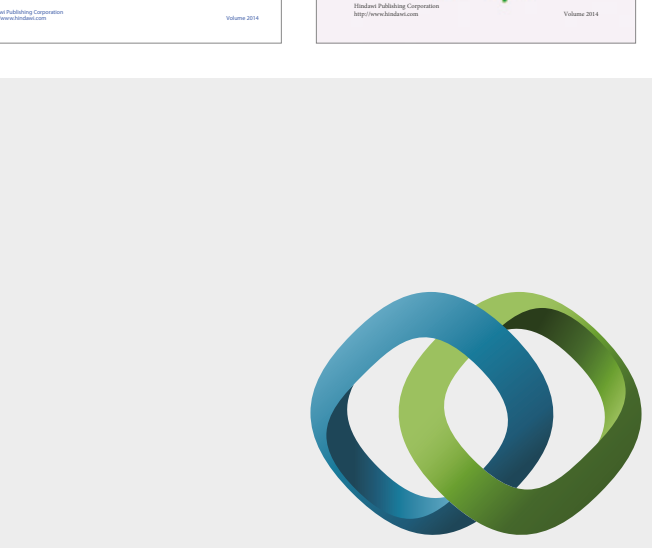

\section{Hindawi}

Submit your manuscripts at

https://www.hindawi.com
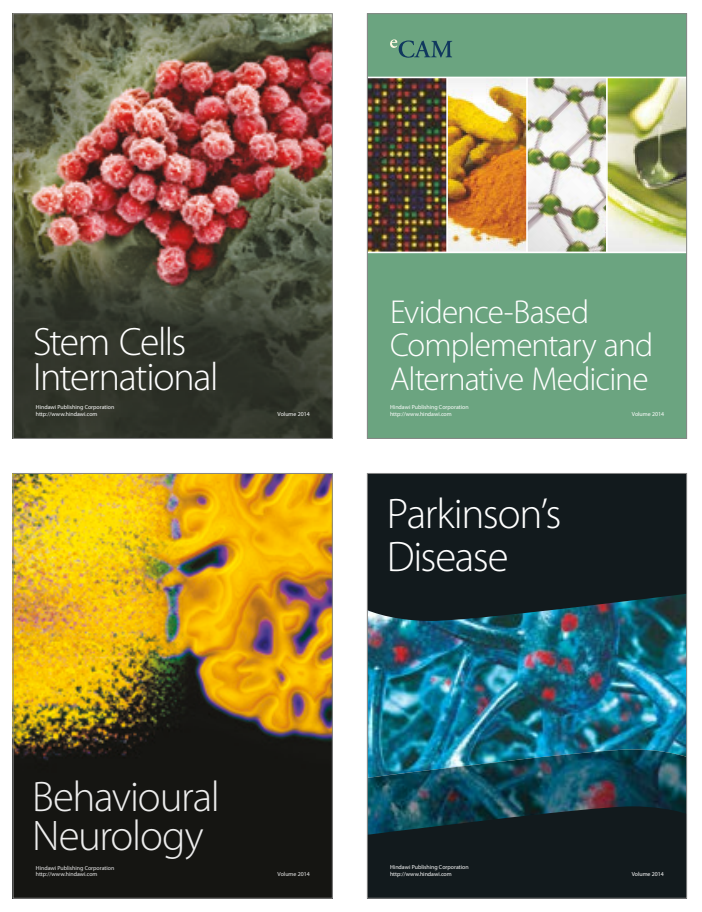
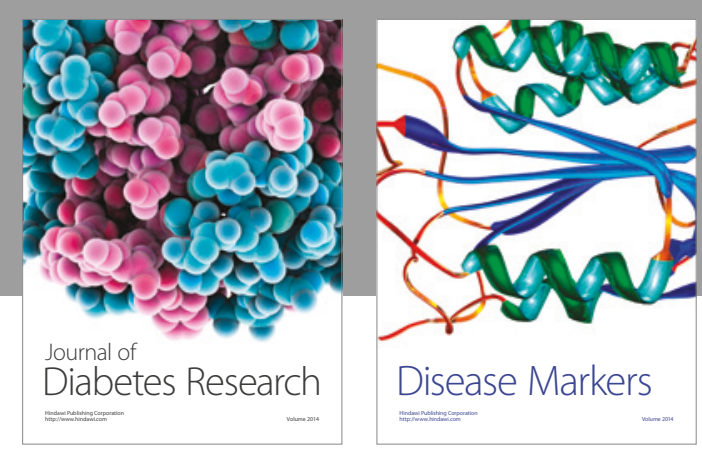

Disease Markers
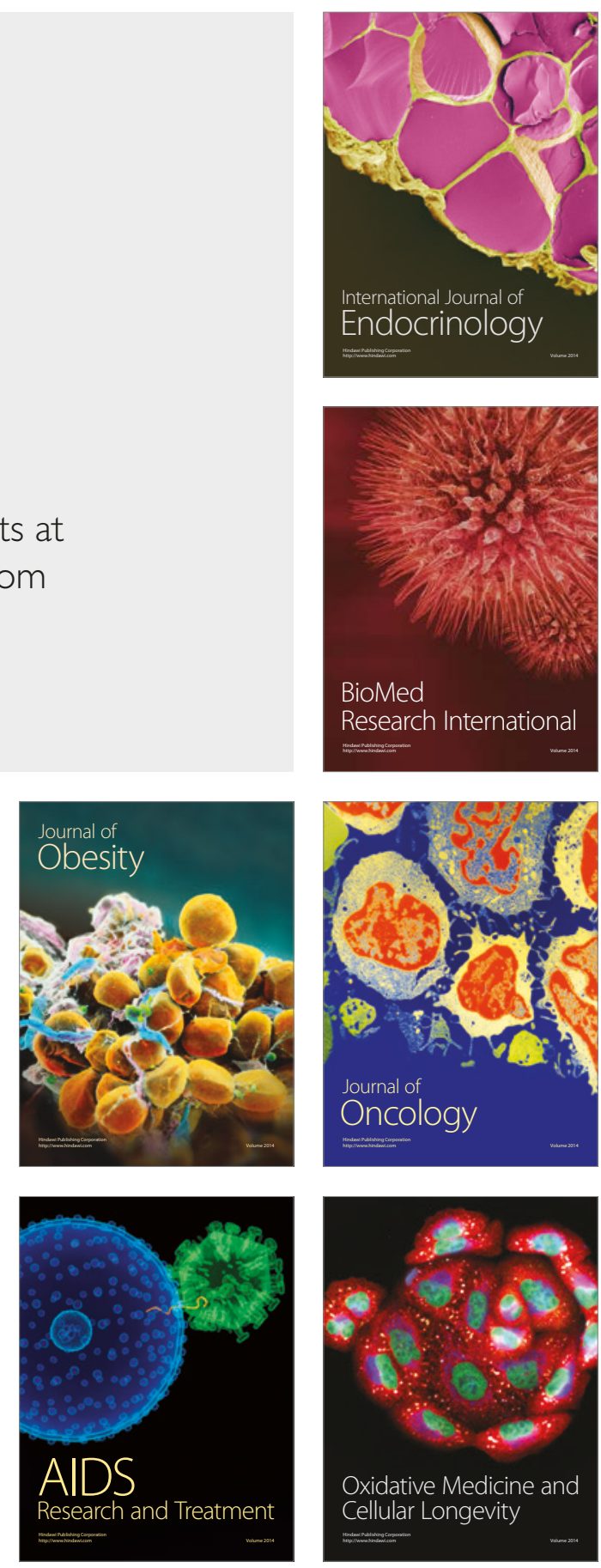